\title{
Chemical determination of oxygen transfer rates, transfer efficiencies and interphases evoked by aeration elements for liquid flows
}

\author{
M. Höfler ${ }^{1}$, R. Kneer ${ }^{1}$, R. Groß ${ }^{2}$ \& K. Kehrmann ${ }^{3}$ \\ ${ }^{1}$ Institute of Heat and Mass Transfer, RWTH Aachen University, Germany \\ ${ }^{2}$ Faculty of Energy Technology, University of Applied Sciences Aachen, \\ Germany \\ ${ }^{3}$ Doosan Lentjes GmbH, Germany
}

\begin{abstract}
Aeration using bubble clusters is a central practice in biological and industrial process technology. The oxygen transfer capacity of state-of-the-art aeration elements was analysed by means of sulphite $\left(\mathrm{S}^{\mathrm{IV}}\right)$ oxidation in liquid phase. Oxygen transfer rate, oxygen transfer efficiency and specific values for the size of the interphase were derived. Measurements were carried out in a pilot scale seawater flue gas desulphurisation plant, using an aeration basin equipped with a gas-tight cover. Aeration elements representing different types and materials were installed in the basin and fed with pressurised dried air. Liquid temperature and $\mathrm{pH}$ were controlled during experiments. $0.5 \mathrm{~mol} / \mathrm{l}$ sulphite solution was used for the experiments, which were carried out at $p H=9$ and $T_{1}=22-25^{\circ} \mathrm{C}$ in presence of a cobalt catalyst. Under these conditions, the liquid phase mass transfer resistance was negligible, allowing the determination of the interphase. Elements were tested at rates of feed flow $\dot{m}_{\text {air }}=12,18,24 \mathrm{~m}_{\mathrm{STP}}^{3} / \mathrm{h}$. The oxygen consumption due to oxidation of the sulphite, which is a direct measure of the transferred gas flux, was derived by means of two measurement methods: exhaust gas analysis and iodometry. While the results of both methods showed comparable trends, discrepancies in total mass transfer were found, which were attributed to the experimental setup. Results showed significant differences in characteristics of the tested aeration elements. Influences due to assembly regarding the orientation of an element inside an aeration basin were analysed for pipe aerators with doublesided perforation.
\end{abstract}

Keywords: flue gas cleaning, aeration, multiphase flow, gas-liquid mass flux, interphase, oxygen transfer rate, transfer efficiency, bubbles, membrane diffusers. 


\section{Introduction}

Aeration using sub-surface admission of pressurised air is a key technology in both biological and industrial applications. A central aspect is the generation of surfacerich bubble clusters in both stationary and streaming liquids, with the respective characteristics (e.g. bubble shape and size distribution, flow field) having a direct influence on the achievable efficiency. In general, gas-liquid molar flux of a component $A$ (oxygen) depends on several influence parameters, including the unknown specific mass transfer coefficient $k_{\text {tot }}$, the partial pressure $p_{\mathrm{A}}$ (gas phase), Henry's constant $H_{\mathrm{A}}$, the liquid phase bulk concentration $c_{\mathrm{A}}$ and the interphase size $A$

$$
\dot{n}_{\mathrm{A}}=k_{\mathrm{tot}} \cdot A \cdot\left(\frac{p_{\mathrm{A}}}{H_{\mathrm{A}}}-c_{\mathrm{A}}\right) .
$$

The difficulty in scientific analysis of the aeration process is the determination of the interphase in a liquid volume due to the highly dynamic bubble clusters.

The goal of this paper is a quantitative comparison of six different membrane diffuser types (plate and pipe diffusers) with regard to the achieved oxygen transfer rates (OTR) and transfer efficiencies (OTE) at different rates of feed flow $\dot{m}_{\text {air }}=$ $12,18,24 \mathrm{~m}_{\mathrm{STP}}^{3} / \mathrm{h}$. Figure 1 shows a schematic of two diffusers used within this project. To gain a deeper knowledge of the fundamental physics of mass transfer, absolute sizes of the respective interphases of the generated bubble clusters were determined independent from the unknown mass transfer coefficient. It was assessed whether the membrane alignment of pipe diffusers has an influence on the aeration efficiency, figure2. The oxygen fluxes were determined using exhaust gas analysis and iodometry.

\section{Methodology}

Typically, oxygen transport is measured using sulphite oxidation, though experimental conditions differ in literature. Derived OTR and OTE are suitable

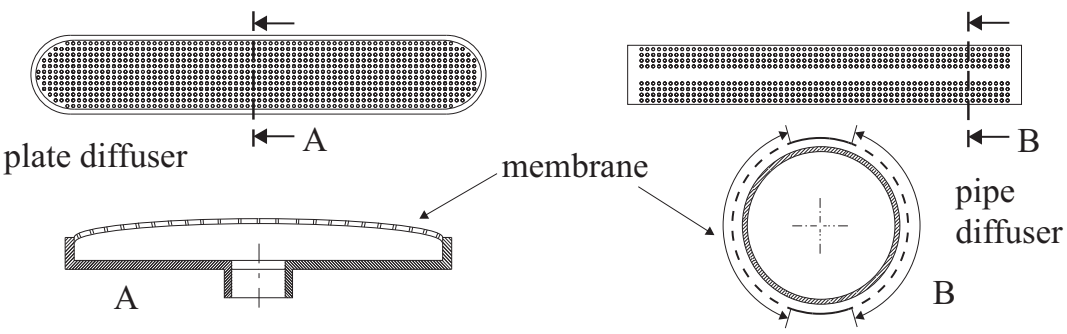

Figure 1: Sample aeration diffusers used within this study (not drawn to scale). 


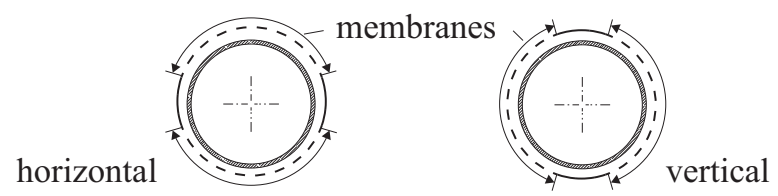

Figure 2: Evaluated membrane alignments on pipe diffusers.

for a qualitative comparison between aeration technologies. Nevertheless, the transferred mass flux is highly dependent on the overall reaction conditions, hindering quantitative analysis. In general, a direct estimation of the interphase $A$ is not possible, as mass transfer coefficient and interphase are not divisible except application of specific ambient conditions.

To allow a quantitative analysis by determination of the interphase, a method based on two-film theory has been developed by Danckwerts [1] utilising the absorption rate of oxygen in a highly concentrated sulphite solution, accompanied by heterogeneous sulphite oxidation. With measurements carried out at $p H=9$, the global model reaction (pseudo second order) for the heterogeneous sulphite oxidation is

$$
\mathrm{SO}_{3(\mathrm{aq})}^{2-}+\frac{1}{2} \mathrm{O}_{2(\mathrm{~g})} \longrightarrow \mathrm{SO}_{4(\mathrm{aq})}^{2-}
$$

Depending upon the ambient conditions, heterogeneous sulphite oxidation is influenced by physical mass transfer and reaction kinetics. Different reaction regimes are used to describe the process, based on the affecting phenomena in a regime. The Hatta number $(\mathrm{Ha})$ comparing the rate of reaction in a liquid film to the rate of diffusion through this film (Bird et al. [2]) is used to define the regimes. Experiments to determine the interphases in multiphase-flows are performed in the fast reaction regime $4(\mathrm{Ha}>3)$, where mass transfer is solely influenced by a superior reaction rate $r$ of $\mathrm{S}^{\mathrm{IV}}$-oxidation compared to the interphase flux. Due to the near instantaneous reaction, oxidation is bounded to the liquid phase boundary layer, where the transferred oxygen (component A) is consumed completely. This results in a liquid bulk concentration of $c_{\mathrm{A}}=0$. As a consequence, the unknown liquid mass transfer resistance (boundary layer) has no influence on the mass transfer rate (Danckwerts [1], Linek and Vacek [3]). The oxygen interphase concentration $c_{\mathrm{A}, 1}^{*}$ is in equilibrium state with the gas bulk phase $p_{\mathrm{A}}$, as the gas phase resistance is negligible (Linek and Mayrhoferová [4], Schultz and Gaden [5]). The respective two-phase concentration profiles for oxygen transfer are shown in figure 3.

Cobalt sulphate catalyst $\left(\mathrm{CoSO}_{4}\right)$ proved to be suitable to achieve adequate reaction rates of the $S^{I V}$-oxidation (Linek and Mayrhoferová [4]). Figure 4 gives a qualitative impression of the absorption rate of oxygen as a function of cobalt catalyst concentration, including the reaction regimes. The relevant fast reaction regime 4 is characterised by a slope of 0.5 .

For a constant concentration in reaction component B (sulphite) throughout the liquid boundary layer, which is equal to the bulk concentration, the reaction is of 


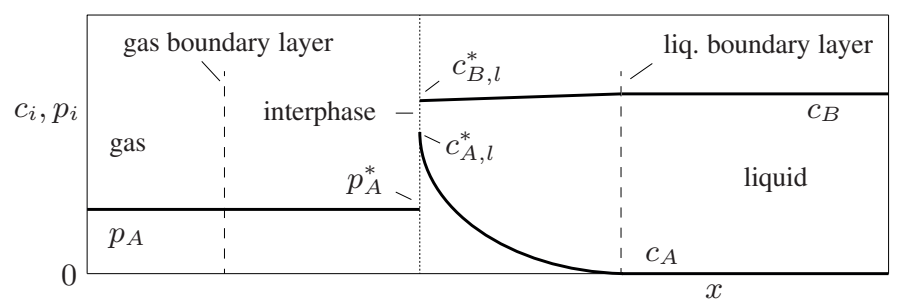

Figure 3: Two-phase concentration profiles for mass transfer of a component A undergoing a reaction of pseudo-second order with $\mathrm{Ha}>3$ (fast reaction regime), Levenspiel [6].

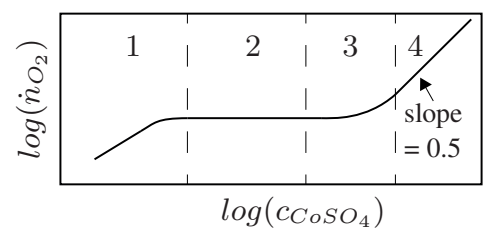

Figure 4: Absorption rate of oxygen as a function of cobalt catalyst concentration (including reaction regimes), Linek and Vacek [3].

zeroth order in sulphite concentration and thus independent of the same, yielding

$$
r=k_{\mathrm{r}} \cdot c_{\mathrm{O}_{2}}^{m} .
$$

Linek and Mayrhoferová [4] showed that eqn (3) is valid for solutions with a total ion concentration $c_{\text {tot }}=c_{\mathrm{Na}_{2} \mathrm{SO}_{3}}+c_{\mathrm{Na}_{2} \mathrm{SO}_{4}}$ within the interval $0.25 \mathrm{~mol} / \mathrm{l}$ $<c_{\text {tot }}<0.5 \mathrm{~mol} / 1$. Experiments in this study were carried out within this range.

Under the described conditions and with respect to the transferred molar oxygen flux $\dot{n}_{\mathrm{O}_{2}}$, the transfer equation can be rearranged to derive the unknown interphase (Danckwerts [1], Linek and Vacek [3])

$$
A=\frac{\dot{n}_{\mathrm{O}_{2}}}{\sqrt{\frac{2 \cdot D_{\mathrm{O}_{2}} \cdot k_{\mathrm{r}} \cdot c_{\mathrm{O}_{2,1}}^{*}}{3}}} .
$$

The respective interphase equilibrium oxygen concentration $c_{\mathrm{O}_{2,1}}^{*}$ was estimated dependent upon the measured mean oxygen concentration in the gas phase. Henry's constant was calculated by

$$
H_{\mathrm{O}_{2}}=5.909 \cdot 10^{-6} \cdot e^{\frac{1602.1}{T_{1}}-\frac{0.9407 \cdot c_{\mathrm{Na}_{2} \mathrm{SO}_{3}}}{1+0.1933 \cdot c_{\mathrm{Na}_{2}} \mathrm{SO}_{3}}}
$$

devised by Linek and Vacek [3] based on experimental data from Linek and Tvrdik [7] and Yasunishi [8]. $D_{\mathrm{O}_{2}}$ was calculated assuming negligible differences in diffusion coefficients between sulphate and sulphite solutions. 
The rate constant describing the heterogeneous sulphite oxidation

$$
k_{\mathrm{r}}=10^{4} \cdot(w \cdot p H-z)^{2} \cdot c_{\mathrm{CoSO}_{4}} \cdot e^{20.512-\frac{6010}{T}}
$$

was calculated with respective constants $(w=22.679, z=160.355)$ for commercially prepared sodium sulphite given by Linek and Mayrhoferová [4].

\section{Experimental setup}

Experiments took place within a gas tight aeration basin $(2.4 m \times 0.45 m \times 1 \mathrm{~m})$ of a pilot scale seawater desulphurisation plant, figure 5. The basin included a cooling system to adjust liquid temperatures. To ensure a stable feed flow rate of moisture free, pressurised air, a digital flow controller was installed. The basin was equipped with stationary probes for $\mathrm{pH}$, temperature and dissolved oxygen, located in the free stream area $0.5 \mathrm{~m}$ above the membrane diffusers.

Liquid samples for iodometry were taken by an automated sampling system at the prescribed measurement locations. The gradient in $\mathrm{S}^{\mathrm{IV}}$-concentration derived by iodometry (redox titration, Mendham and Vogel [9]) is proportional to the transferred oxygen flow (OTR) for homogeneous conditions

$$
\dot{n}_{\mathrm{O}_{2}}=\frac{1}{2} \cdot \frac{d}{d t} c_{\mathrm{S}} \mathrm{IV} .
$$

In addition, exhaust gas analysis was used to measure volumetric $\mathrm{O}_{2}, \mathrm{CO}_{2}$ and $\mathrm{SO}_{2}$ contents (dry). Conditions at the outlet of the basin were successively calculated under the assumption of a relative air humidity equal to one due to gas-liquid interaction. Experiments within this study were carried out using high concentrated sulphite solutions prepared with deionised water and commercial sodium sulphite $\left(\mathrm{Na}_{2} \mathrm{SO}_{3}\right)$. In experiments prior to this work, a catalyst concentration $c_{\mathrm{CoSO}_{4}}=1 \cdot 10^{-4} \mathrm{~mol} / \mathrm{l}$ was identified to be sufficient for the experimental setup, figure 6. Experiments were run at $T_{1}=22-25^{\circ} \mathrm{C}$ and $\mathrm{pH}$ $=9$.

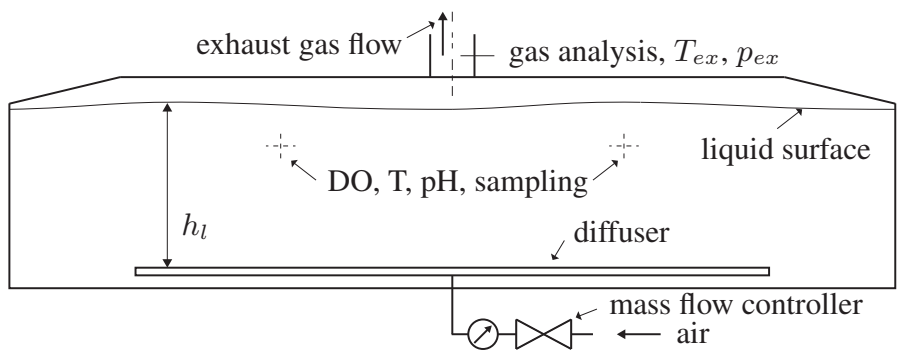

Figure 5: Experimental setup for aeration experiments (sectional view). 


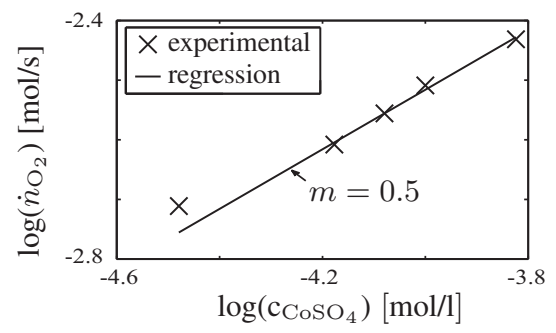

Figure 6: Experimental determination of catalyst concentration $\left(c_{\mathrm{CoSO}_{4}}\right)$.

\section{Results}

Table 1 consists of data from the experiments carried out in the course of this study. An experiment with liquid temperatures exceeding the defined range $T_{1}=$ $22-25^{\circ} \mathrm{C}$ was included to assess the influence of the temperature. Interphases, oxygen transfer rates and oxygen transfer efficiencies are reviewed as total values to assess the general characteristics of six different diffusers. All results concerning oxygen transfer rates and oxygen transfer efficiencies are made relative to reference plate diffuser 1 at a feed air flow rate $\dot{m}_{\text {air }}=12 \mathrm{~m}_{\mathrm{STP}}^{3} / \mathrm{h}$ (reference setup).

Table 1: Experiments carried out within this study.

\begin{tabular}{|l|l|l|l|l|}
\hline Diff. & Type & Material & Area & Comments \\
\hline 1 & Plate & Ethylene propylene diene monomer & $0.2 \mathrm{~m}^{2}$ & Reference design \\
\hline 1 & Plate & Ethylene propylene diene monomer & $0.2 \mathrm{~m}^{2}$ & $T_{1}=25-35^{\circ} \mathrm{C}(\mathrm{ht})$ \\
\hline 2 & $\begin{array}{c}\text { Oval } \\
\text { pipe }\end{array}$ & Ethylene propylene diene monomer & $0.12 \mathrm{~m}^{2}$ & \\
\hline 3 & Pipe & Ethylene propylene diene monomer & $0.2 \mathrm{~m}^{2}$ & \\
\hline 4 & Pipe & Silicone & $0.15 \mathrm{~m}^{2}$ & Vertical membr. \\
\hline 4 & Pipe & Silicone & $0.15 \mathrm{~m}^{2}$ & Horizontal membr. \\
\hline 5 & Pipe & Silicone & $0.3 \mathrm{~m}^{2}$ & \\
\hline 6 & Pipe & Ethylene propylene diene monomer & $0.245 \mathrm{~m}^{2}$ & \\
\hline
\end{tabular}

\subsection{Comparison of results measured by iodometry and gas analysis}

As a remarkable result of the measurements a significant difference concerning the transferred oxygen mass flux derived by means of iodometry and gas analysis was found. Data in table 2 reveal that iodometry resulted in higher yields of oxygen mass fluxes than exhaust gas analysis at each operating point. 
Table 2: Related oxygen transfer rates derived by exhaust gas analysis (EGA) and iodometry (IOD).

\begin{tabular}{|l|l|l|l|l|l|l|}
\hline \multirow{2}{*}{} & \multicolumn{2}{|c|}{$12 \mathrm{~m}_{\mathrm{STP}}^{3} / \mathrm{h}$} & \multicolumn{2}{c|}{$18 \mathrm{~m}_{\mathrm{STP}}^{3} / \mathrm{h}$} & \multicolumn{2}{c|}{$24 \mathrm{~m}_{\mathrm{STP}}^{3} / \mathrm{h}$} \\
\cline { 2 - 7 } & EGA & IOD & EGA & IOD & EGA & IOD \\
\hline Diffuser 1 [\%] & 100.0 & 134.9 & 109.1 & 153.2 & 111.7 & 112.6 \\
\hline Diffuser 1 (ht) [\%] & 182.4 & 248.0 & 237.6 & 275.1 & 280.9 & 353.8 \\
\hline Diffuser 4 (vert.) [\%] & 77.2 & 112.3 & 95.5 & 128.7 & 111.6 & 180.5 \\
\hline
\end{tabular}

The general trend was comparable for both measurement techniques, although slight discrepancies were found, which could be attributed to the experimental setup. Different flow patterns arise due to design details of the diffusers. As oxygen is consumed instantly once transferred over the boundary surface, local deviations in specific interphase $A$, OTR and thus OTE result. The magnitude of deviations is a characteristic of the different diffusers. From visual observation, a well aerated region is expected upstream of the elements' membranes (e.g. position of sampling and measurement, figure 5). On the contrary, wall regions next to the ends of an aerator suffer from less oxygen supply due to the small rate of flow there.

Gas analysis utilises the total exhaust gas flow for mass balancing. Errors are mainly limited to the assumption of saturated conditions with regard to air humidity. As no specific concentrations are derived, there is no influence of local deviations on interphase mass flux. In contrast, sampling for iodometry takes place at two positions, figure 5, leading to a determination of the local mass flux. Assuming a homogeneous mixture of the fluid, the derived specific values from the well aerated regions are accordingly extrapolated onto the total liquid volume of the basin, resulting in a general overestimation of the mass fluxes.

As a consequence, gas analysis can be treated as more accurate than iodometry. The following results and discussions are therefore based upon gas analysis results.

\subsection{Oxygen transfer rate (OTR)}

Oxygen transfer rates are highly dependent upon the diffuser feed mass flows, with an overall increase found for higher flows, figure 7. Slopes and characteristics of the transfer curves differ significantly between the elements.

For the reference diffuser 1 only a small change in the transfer flux was found (11\%) with doubling of the feed flow, compared to the reference admission. Absolute values were generally low compared to the remaining devices. While there was a noticeable change of the OTR in the region of reduced feed flow $\left(12-18 \mathrm{~m}_{\mathrm{STP}}^{3} / \mathrm{h}, \Delta \mathrm{OTR}=9 \%\right)$, a further increase of the flow resulted in minor changes to the transfer flux $(\Delta \mathrm{OTR}=2 \%)$.

A significant temperature influence on mass transfer was found for the high temperature test run with diffuser $1(\mathrm{ht})$. Compared to the reference experiment, all 


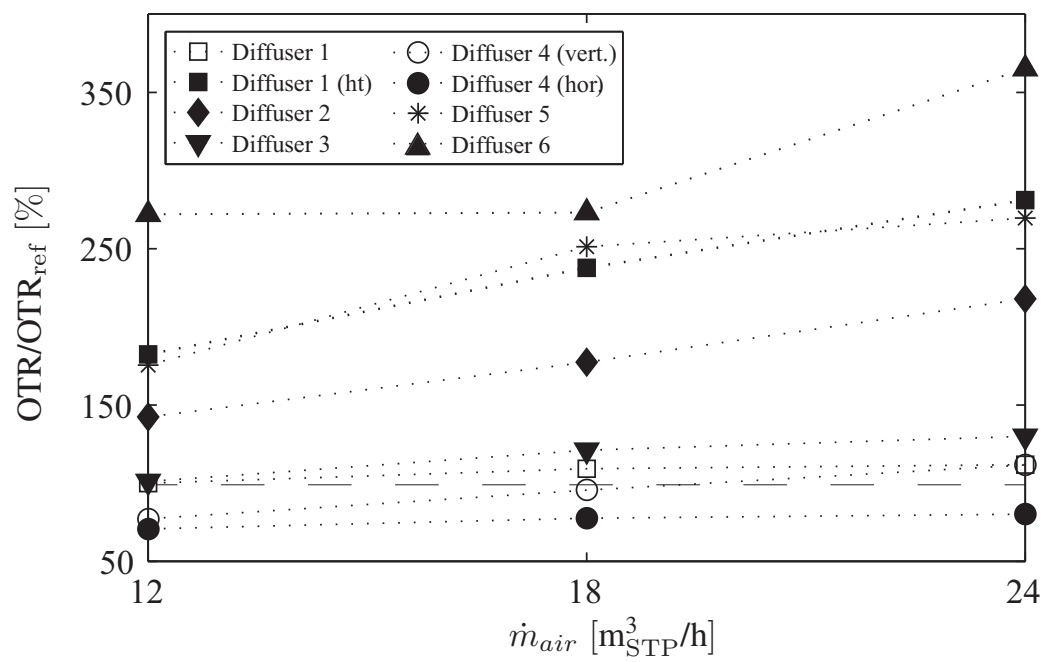

Figure 7: Oxygen transfer rate (OTR) as a function of aeration flow rate standardized to the reference diffuser 1 .

parameters with exception of temperature, which increased during the run, showed identical trends.

With exception of diffuser 4, all pipe aerators achieved higher absolute transfer rates compared to the reference plate diffuser 1 , though diffusers 3 and 4 only differed slightly. On the other hand, the diffusers 2 and 5 showed considerable higher oxygen transfer rates. When comparing the characteristics, it became evident that diffuser 5 exhibited a remarkably strong increase of OTR in low feed flow regions, while there was almost no further increase for higher flow rates. Diffuser 6 allowed for the highest absolute transfer rates. Here, stagnation was found for low level feed flows, followed by a strong increase for higher flow rates. Transfers rates at $\dot{m}_{\text {air }}=24 \mathrm{~m}_{\mathrm{STP}}^{3} / \mathrm{h}$ were more than tripled compared to the reference element.

Experiments revealed that membrane alignment (figure 2) had a determinable influence regarding the oxygen transfer rate of pipe diffusers. While OTR was comparable at low level feed flow rates, discrepancies were found for increased flow rates. For the setup with membranes vertically orientated (diffuser 4 (vert.)), OTR was enhanced by $48 \%$ with regard to a doubling of the feed flow rate. If the membranes were aligned horizontally (diffuser 4 (hor.)), OTR only differed by $13 \%$ with doubled feed flow rate.

\subsection{Measurement of interphases in multiphase flows}

The general trends of the interphase size and OTR were comparable for all diffusers investigated, figure 8. Diffusers 2, 5 and 6 caused significantly larger 


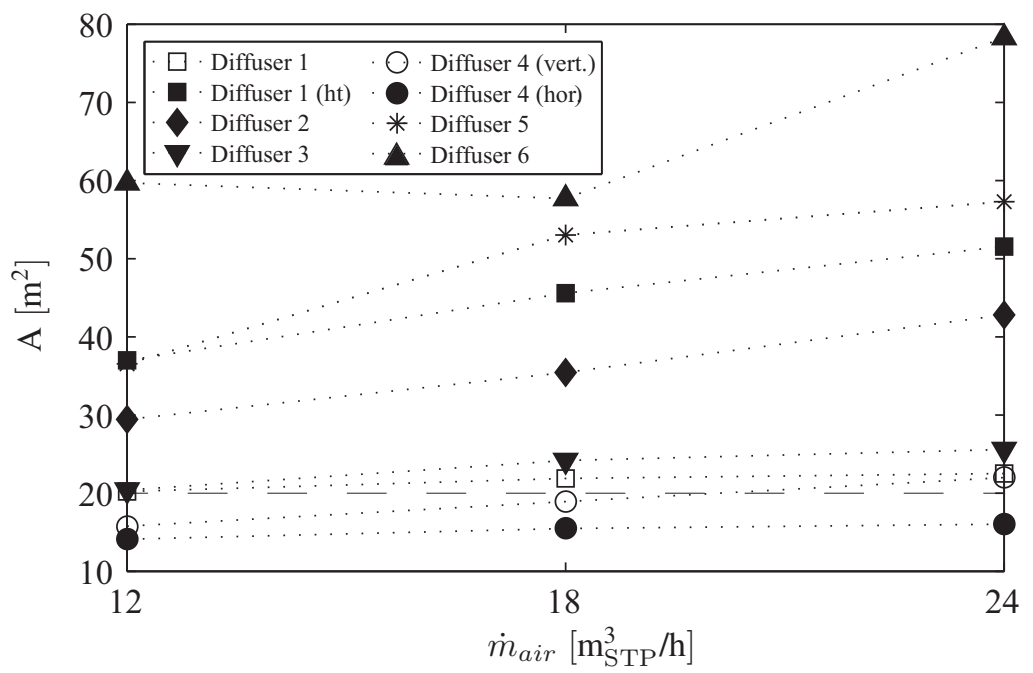

Figure 8: Measured absolute interphase sizes $A$ as function of aeration flow rate.

interphases compared to the reference diffuser, whereas both pipe diffusers 3 and 4 were found to be at a comparable level. The results proved that due to the prevailing ambient conditions $\left(p H=9, T_{1}<25^{\circ} \mathrm{C}, D O=0 \%\right)$ the transferred gas flux was merely depending on the interphase size.

Nevertheless, some differences between trends of oxygen transfer rates and interphases were found. Comparison of the high temperature experiment (diffuser 1 (ht)) and the reference case (diffuser 1) revealed a large influence of the temperature on the entire process. According to figures 7 and 8 , higher temperatures led to an increase of the oxygen transfer rate and the interphase at constant feed flows. Nonetheless, a significant deviation between the increase in both parameters was detected (table 3). Calculated from eqn (6), liquid temperatures exceeding $T_{1}=25^{\circ} \mathrm{C}$ led to a strong increase of the reaction constant $k_{\mathrm{r}}$, which resulted in an underestimation of the interphase, while OTR was identified correctly.

Table 3: Influence of liquid temperatures on relative deviation between oxygen transfer rate and interphase due to increase of feed flow rates.

\begin{tabular}{|l|l|l|l|}
\hline & $12-18 \mathrm{~m}_{\mathrm{STP}}^{3} / \mathrm{h}$ & $18-24 \mathrm{~m}_{\mathrm{STP}}^{3} / \mathrm{h}$ & Comment \\
\hline Diffuser 1 [\%] & 1.0 & -0.5 & $T_{1}=22-25^{\circ} \mathrm{C}$ \\
\hline Diffuser 1 (ht) [\%] & 7.0 & 7.6 & $T_{1}=25-35^{\circ} \mathrm{C}$ \\
\hline Diffuser 3 [\%] & 1.3 & 1.8 & $T_{1}=22-25^{\circ} \mathrm{C}$ \\
\hline
\end{tabular}


In compliance with the OTR-analysis, interphase size was not increasing for small feed flow rates for the diffuser 6 . A possible explanation could be an increase in bubble diameters due to increased flow rates being the dominant phenomenon here, yielding a constant total surface, as specific bubble interphases per volume decreased. For higher feed flow rates $\left(\dot{m}_{\text {air }}>18 \mathrm{~m}_{\mathrm{STP}}^{3} / \mathrm{h}\right)$, the total number of bubbles increased significantly, leading to measurable changes of the interphase.

Regarding the alignment of membranes, a configuration using membranes aligned horizontally on pipe diffusers led to a significant reduction of interphase size compared to a vertical setup.

The general increase of available interphase with enhanced feed flow rates is based on two phenomena. In addition to the generation of higher bubble numbers it became evident that high mass flows led to the formation of large scale eddies in the basin. Mean residence times of bubbles were prolonged as these currents affected smaller bubbles, dragging them into the solution. Thus, the overall gascontent was increased as bubbles were transported to areas which were otherwise bubble-free. Larger bubbles, mainly found in the central upstream, rapidly left the water, as their drag was too high to be affected by the surrounding flow patterns.

Important findings of this work were the specific characteristics of the tested diffusers concerning the evoked bubble dimensions. Elements arousing comparably large interphases $(2,5,6)$ produced mainly small bubbles. In comparison to elements generally evoking larger bubbles $(1,3,4)$, these diffusers faced stronger changes in both OTR and interphase with increased feed flow rates.

\subsection{Oxygen transfer efficiency (OTE)}

The oxygen transfer efficiency is defined as the ratio of the OTR to the total rate of $\mathrm{O}_{2}$ inserted into the liquid. For all experiments conducted, OTE declines with higher aeration mass flows, figure 9. Significant differences of the oxygen transfer efficiency are found for the tested diffusers, concerning both absolute levels and characteristics. Low efficiency elements include plate diffuser 1 and the pipe aerators 3 and 4, showing approximately linear changes. On the other hand, diffusers 2, 5 and 6 achieve much higher values of OTE.

Characteristics could be described by means of OTR and interphase findings. Reference diffuser 1 showed a strong decrease in OTE with increased feed flow rates due to its nearly constant oxygen transfer rate. A comparable behaviour was found for diffuser 3. Diffuser 6 achieved the best values in our research. Due to the constant oxygen transfer rate, a strong decrease in efficiency was detected for feed flows between 12-18 $\mathrm{m}_{\mathrm{STP}}^{3} / \mathrm{h}$. For higher flow rates, the oxygen transfer efficiency stabilized at a high level, as both parameters increased rapidly. Highest efficiencies were found for small flows with large interphases due to small bubble sizes. For diffuser 5, a decrease was found for flow rates $\dot{m}_{\text {air }}>18 \mathrm{~m}_{\mathrm{STP}}^{3} / \mathrm{h}$ due to a smaller slope in OTR.

Following the OTR-characteristics, OTE was affected by the orientation of the aerator as well. For the horizontal orientation, lower efficiencies and a stronger load dependent decrease in OTE were found compared to the vertical setup. 


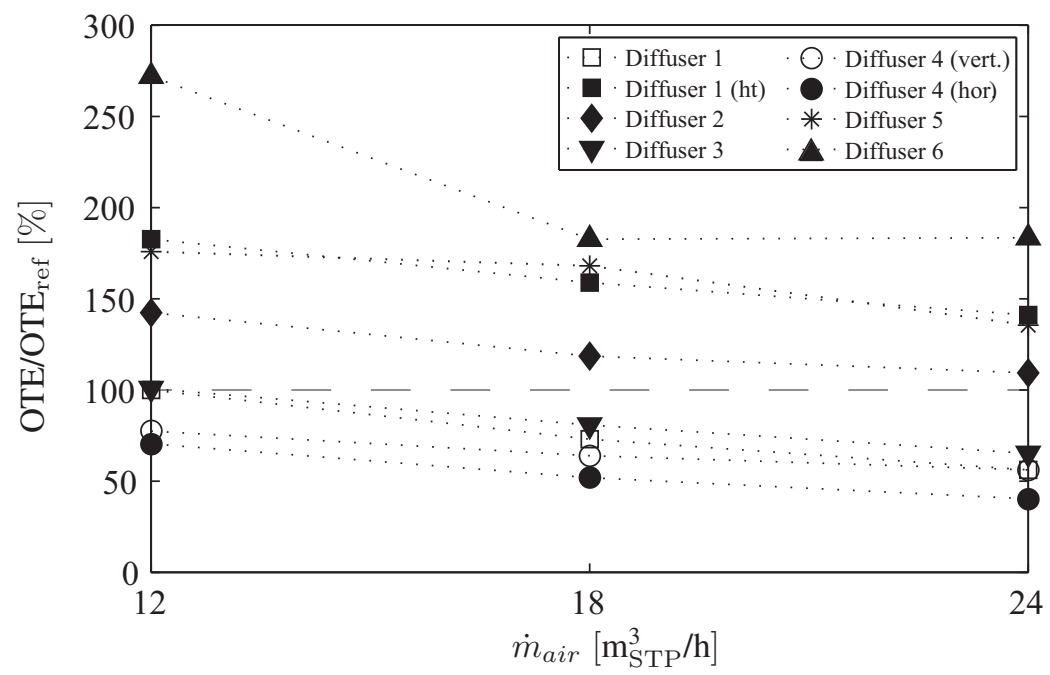

Figure 9: Oxygen transfer efficiency (OTE) as function of aeration flow rate standardized to the reference case (diffuser 1).

\section{Conclusion}

Pilot scale experiments were carried out to evaluate the differences between aeration diffusers. Derived characteristics and relative comparisons allowed identification of suitable technologies. Diffusers were compared with regard to oxygen transfer rate and interphases, measured at different feed flow rates. Experiments were carried out applying defined ambient conditions $\left(p H=9, T_{1}=\right.$ $22-25^{\circ} \mathrm{C}, D O=0 \%$ and in presence of cobalt catalyst. For evaluation, an ethylene propylene diene monomer rubber membrane (EPDM) plate diffuser was used as reference technology.

Experiments showed that gas analysis was suitable for both interphase and oxygen transfer rate determination, which allowed an abandonment of iodometry. Furthermore, adulterant influences of the experimental setup on iodometry were identified, as iodometry required a homogeneous mixture of the fluid, which was difficult to ensure.

It was found that the pipe diffusers 5 and 6 allowed for results superior to the reference setup, whereas the performances of the remaining diffusers were found to be within the reference range. In addition, experiments revealed that membrane orientation is a very important factor regarding pipe aerators. It was proven that bottom membranes gave almost no benefit at all, which resulted in smaller OTR and OTE in addition to a lower increase of aeration at higher loads. This aspect has to be considered when using these kinds of pipes, as correct orientation has to be assured to avoid economic affections and efficiency problems. 


\section{Nomenclature}

\section{Indices}

* equilibrium state

air aeration feed flow

$a q$ aqueous

$A, B$ component

ex exhaust conditions

$g$ gaseous

hor. horizontal

$l$ liquid

ref reference setup

tot total

vert. vertical

\section{Symbols}

$\dot{m}$ mass flux

$\dot{n}$ molar flux

$A$ interphase extent

$c$ concentration

Co cobalt

$\mathrm{CO}_{2}$ carbon dioxide

$D$ diffusion coefficient
$D O$ dissolved oxygen

[\%]

[-] EGA exhaust gas analysis

[-] $H$ Henry's constant

[-]

[-] Ha Hatta number

[mol/atm]

[-] IOD iodometry

[-] $\quad k$ mass transfer coeff.

$[-]$

[-] $\quad k_{r}$ rate constant

[-] $m$ reaction order

$[\mathrm{m} / \mathrm{s}]$

[-] $\mathrm{Na}$ sodium

dep.]

[-] $\mathrm{O}_{2}$ oxygen

$[-]$

[-] OTE oxygen transfer efficiency [\%]

[-] OTR oxygen transfer rate $\quad[\mathrm{mg} / \mathrm{s}]$ $p$ partial pressure

[Pa]

$\left[\mathrm{m}_{\mathrm{STP}}^{3} / \mathrm{h}\right] \quad p H \mathrm{pH}$

$[\mathrm{mol} / \mathrm{s}] \quad r$ reaction rate

$\left[\mathrm{m}^{2}\right] \quad S^{I V}$ tetravalent sulphur

$[\mathrm{mol} / \mathrm{sl}]$

[mol/l] $\mathrm{SO}_{2}$ sulphur dioxide

$[-]$

[-] $\mathrm{SO}_{3}^{2-}$ sulphite

[-] $\mathrm{SO}_{4}^{2-}$ sulphate

$[\mathrm{m} / \mathrm{s}] \quad T$ temperature

\section{Acknowledgements}

Fundings by the German Federal Ministry of Education and Research (IngenieurNachwuchs 2012 - 03FH010I2) and support of Doosan Lentjes GmbH, Ratingen are greatly acknowledged.

\section{References}

[1] Danckwerts, P.V., Gas-liquid reactions. McGraw-Hill chemical engineering series, McGraw-Hill Book Co., 1970.

[2] Bird, R.B., Stewart, W.E. \& Lightfoot, E.N., Transport phenomena. Wiley, 2007.

[3] Linek, V. \& Vacek, V., Chemical engineering use of catalyzed sulfite oxidation kinetics for the determination of mass transfer characteristics of gas-liquid contactors. Chemical Engineering Science, 36, pp. 1747-1768, 1981.

[4] Linek, V. \& Mayrhoferová, J., The kinetics of oxidation of aqueous sodium sulphite solution. Chemical Engineering Science, 25(I), pp. 787-800, 1970.

[5] Schultz, J.S. \& Gaden, E.L., Sulfite Oxidation as a Measure of Aeration Effectiveness. Industrial \& Engineering Chemistry, 48(12), pp. 2209-2212, 1956. 
[6] Levenspiel, O., Chemical reaction engineering. John Wiley \& Sons, 3rd edition, 1999.

[7] Linek, V. \& Tvrdik, J., A generalization of kinetic data on sulphite oxidation systems. Biotechnology and Bioengineering, 13(3), pp. 353-369, 1971.

[8] Yasunishi, A., Solubilities of sparingly soluble gases in aqueous sodium sulfate and sulfite solutions. Journal of Chemical Engineering of Japan, 10(2), pp. 89-94, 1977.

[9] Mendham, J. \& Vogel, A., Vogels textbook of quantitative chemical analysis. Prentice Hall, 2006. 